\title{
Vamos falar sobre ciganos? Projetos educacionais, representações e a desconstrução do estigma no ambiente escolar
}

\author{
Let's talk about gypsies? Educational projects, representations
}

and the deconstruction of stigma in the school environment

¿Hablamos de gitanos? Proyectos educativos, representaciones y la deconstrucción del estigma en el ámbito escolar

RODRIGO MARQUES LEISTNER

Mabielle Pedra FAntI (Db

\section{Resumo}

O artigo aborda as complexidades que envolvem a inserção de temáticas como "povos ciganos" e "cultura cigana" no campo educacional. Tomando como ponto de partida o histórico de ações e caracterizações preconceituosas acerca desses povos na sociedade envolvente, o texto problematiza as formas através das quais essas realidades tensas podem ser "negociadas" no âmbito da escola, a partir de duas perspectivas: (i) avaliar o modo como as representações pejorativas acerca dos ciganos e suas culturas se atualizam no ambiente escolar; (ii) verificar as possibilidades de desconstrução daquelas representações a partir da realização de projetos educacionais específicos. Para tanto, em conjunto com revisão da literatura especializada e observação de dados secundários, analisou-se um conjunto de atividades pedagógicas dedicadas às questões étnico-raciais e à temática cigana empreendidas em uma Escola Municipal de Ensino Fundamental da rede pública da cidade de Rio Grande, região sul do Rio Grande do Sul. Se por um lado evidencia-se a persistência de representações negativas acerca dos sujeitos e cultura cigana em certas comunidades escolares, avalia-se que determinados projetos educacionais

\footnotetext{
a Universidade Federal do Rio Grande (FURG), Rio Grande, RS, Brasil. Doutor em Ciências Sociais, e-mail: rodrigoless@yahoo.com.br

b Universidade Federal de Pelotas (UFPEL), Pelotas, RS, Brasil. Mestra em Sociologia, e-mail: mabiellepedra.adv@gmail.com
} 
potencializam o papel integrador da escola a partir de processos de reconhecimento dos diferentes saberes e da diversidade cultural e étnica da sociedade brasileira.

Palavras-chave: Ciganos. Representações sociais. Estigma. Relações étnico-raciais. Projetos educacionais.

\begin{abstract}
The paper addresses the complexities that involve the insertion of themes such as "gipsy peoples" and "gipsy culture" in the educational field. Taking as a starting point the history of prejudiced actions and characterizations about these peoples in the wider society, the text problematizes the ways in which these tense realities can be "negotiated" within the school, from two perspectives: (i) evaluate how the pejorative representations about gypsies and their cultures are updated in the school environment; (ii) verify the possibilities of deconstructing those representations from the realization of specific educational projects. To this end, together with a review of the specialized literature and observation of secondary data, a set of pedagogical activities devoted to ethnic-racial issues and the gypsy theme was undertaken in a Municipal Elementary School in the public network of the city of Rio Grande, south region of Rio Grande do Sul. If, on the one hand, the persistence of negative representations about the subjects and gypsy culture in certain school communities is evident, it is assessed that certain educational projects enhance the integrating role of the school through processes of recognition different knowledge and the cultural and ethnic diversity of Brazilian society.
\end{abstract}

Keywords: Gypsies. Social representations. Stigma. Ethnic-racial relations. Educational projects.

\title{
Resumen
}

El artículo aborda las complejidades que implican la inserción de temas como "pueblos gitanos" $y$ "cultura gitana" en el ámbito educativo. Tomando como punto de partida la historia de acciones y caracterizaciones prejuiciadas sobre estos pueblos en la sociedad circundante, el texto cuestiona las formas en las que estas tensas realidades pueden ser "negociadas" dentro de la escuela, desde dos perspectivas: (i) evaluar cómo se actualizan en el entorno escolar las representaciones peyorativas sobre los romaníes y sus culturas; (ii) verificar las posibilidades de deconstruir esas representaciones a partir de la realización de proyectos educativos específicos. Para ello, junto con una revisión de la literatura especializada y la observación de datos secundarios, se analizado un conjunto de actividades pedagógicas dedicadas a la temática étnico-racial y la temática gitana desarrolladas en una Escuela Primaria Municipal de la red pública de la ciudad de Rio Grande, región sur de Rio Grande do Sul. Si, por un lado, se evidencia la persistencia de representaciones negativas sobre los sujetos y la cultura gitana en ciertas comunidades escolares, se estima que ciertos proyectos educativos potencian el rol integrador de la 
escuela a través de procesos de reconocimiento de los diferentes saberes y diversidad cultural y étnica de la sociedad brasileña.

Palabras clave: Gitanos. Representaciones sociales. Estigma. Relaciones étnico-raciales. Proyectos educativos.

\section{Introdução}

Quando falamos sobre ciganos mobilizamos um quadro amplo de referências simbólicas associadas a um conjunto de representações mais ou menos estáveis, as quais, em grande medida, nem sempre se organizaram de modo positivo e a partir da agência das próprias coletividades representadas (MOSCOVICI, 2009; FAZITO, 2006) ${ }^{1}$. De qualquer modo, sabe-se que, ao longo de sua história e em todo o mundo ocidental, em virtude dessas representações o povo cigano experimentou largos processos de marginalização e exclusão social; e boa parte desses processos decorreu de percepções acerca de características centrais de sua cultura, caso do nomadismo, por exemplo, dificilmente aceito em sociedades nas quais aqueles grupos circulavam de modo sazonal ao longo de sua diáspora.

É num contexto de aparente oposição ao ordenamento social ou em relação a aspectos culturais hegemônicos da ideia de modernidade (emergindo como supostamente arcaicos e indomináveis) ${ }^{2}$ que ciganos passam a ser perseguidos e massacrados, sendo então categorizados como "bandidos", "mentirosos" e "enganadores", entre outros tantos marcadores projetados sobre uma identidade deteriorada e manipulada por segmentos hegemônicos da sociedade envolvente (GOFFMAN, 2017). Dito de outro modo, trata-se de representações sociais inseridas

\footnotetext{
1 Segundo Moscovici (2009), as percepções ocidentais da "identidade cigana" partem de uma espécie de "nó figurativo" (complexo arranjo de representações) no qual encontram-se diversas categorias depreciativas. Perceber essas relações de poder, no entanto, não significa negar certas estabilidades contidas em arranjos identitários configurados a partir das próprias coletividades. Assim, segundo Mazurana, Dias e Laureano (2016), quando mencionamos a ideia de "grupos ciganos" fazemos referência a determinadas regiões de origem e marcadores linguísticos e culturais característicos, apontando três grandes grupos ciganos presentes no Brasil: os Rom, Calon e Sinti, além dos correspondentes subgrupos e clãs.

${ }^{2}$ Como exemplo dessas ideias, cabe retomar que "o nomadismo é totalmente antiético em relação à forma de estado moderna. E esta se preocupa constantemente em suprimir o que considera a sobrevivência de um modo de vida arcaico [sendo que...] fixar significa a possibilidade de dominar" (MAFFESOLI, 2001, p. 24).
} 
e engessadas no senso comum, passando de geração a geração e assim contribuindo para a manutenção do estigma historicamente associado às subjetividades ciganas ${ }^{3}$.

Com base nesses processos tensos e dramáticos de constituição do estigma, através dos quais se estabelecem lógicas de descrédito social do indivíduo cigano, reforçam-se os processos de exclusão que potencialmente promovem o afastamento dessas minorias em relação ao Estado, obstaculizando-se assim o acesso a políticas públicas, direitos básicos e garantias fundamentais das condições de cidadania. E para os propósitos desse artigo, é com base na noção de que parte desses direitos e garantias podem ser viabilizados no âmbito da educação que propomos avaliar o modo como as tensões sociais aqui referidas se reproduzem nos espaços escolares.

Nesse sentido, este trabalho busca analisar as complexidades que envolvem a inserção de temáticas como "povos ciganos" e "cultura cigana" no campo educacional brasileiro. Tomando como ponto de partida o histórico de ações e representações preconceituosas acerca desses povos e sua cultura na sociedade envolvente, o texto problematiza as formas através das quais essas realidades tensas podem ser "negociadas" no âmbito da escola, a partir de duas perspectivas: (i) compreender o modo como aquele conjunto de representações negativas se atualiza no ambiente escolar, aqui observando-se as percepções, discursos e noções mais gerais enunciadas por alunos e demais atores sociais membros de determinadas comunidades escolares; (ii) verificar as possibilidades de desconstrução daquelas mesmas representações a partir da realização de projetos educacionais específicos, considerando-se este mesmo ambiente e os atores envolvidos com os referidos projetos.

Destaque-se que o interesse sobre a temática aqui abordada decorre da realização de incursões etnográficas empreendidas sistematicamente ao longo dos últimos quatro anos junto a grupos ciganos localizados na metade sul do Rio Grande do Sul. No contato com a realidade empírica disponível, na qual são investigados processos mais amplos de sedentarização de grupos ciganos na região ${ }^{4}$, foram diversas

\footnotetext{
${ }^{3}$ De acordo com Goffman, o estigma articula simbolicamente uma relação entre atributo e estereótipo, levando a representações associadas e emprenhadas no descrédito social do indivíduo ou grupo estigmatizado (GOFFMAN, 2017, p. 13).

${ }^{4}$ Essas pesquisas têm sido realizadas entre os anos 2018 e 2021, no contexto dos estudos de pós-graduação de uma das autoras do artigo, conforme atividades acadêmicas vinculadas ao PPG Sociologia (Lato Sensu) da Universidade Federal do Rio Grande (FURG) e
} 
as referências acerca das problemáticas enfrentadas por aqueles agentes em suas lógicas de aproximação com o campo educacional. Tal percepção deslocou parte dos esforços investigativos mais amplos para o contato direto com as comunidades escolares locais, o que possibilitou acesso a um projeto educacional específico e articulado por demandas como pluralismo e aceitação da diferença no contexto das relações étnico-raciais, tendo como parte de seus escopos a questão dos povos e culturas ciganas. Esse projeto foi realizado em Escola de Ensino Fundamental da rede pública da cidade de Rio Grande, em 2016, tendo como metodologia atividades de pesquisa e mostra de trabalhos sobre "povos e cultura cigana" através de ações práticas elaboradas por diferentes grupos de alunos.

Foi sobre o conjunto de ações desenvolvidas no âmbito deste projeto educacional que se realizou pesquisa exploratória cujos dados municiam parte da reflexão aqui desenvolvida. A esses dados primários - coletados mediante entrevistas semidiretivas aplicadas aos participantes do projeto - somam-se informações oriundas do trabalho de campo etnográfico realizado com grupos ciganos presentes na região, além da referência a dados secundários importados da literatura disponível e focada em temáticas similares ${ }^{5}$.

Do ponto de vista teórico, nossa abordagem parte de uma perspectiva na qual a realidade é sempre um processo articulado por negociações tensas, cujas possibilidades de definição dependem de arranjos e interações múltiplas (THOMAS, 2005; BERGER; LUCKMANN, 2002). Isso supõe colocar o conceito de representações sociais, conforme elaborado por Moscovici (2003), no centro de nossa análise, propondo-se que as iniciativas de definição (representação) que os diferentes grupos e categorias sociais fazem de si e dos outros (bem como de suas culturas) configuram-se como formulações provisórias e situacionais, as quais sofrem

PPG Sociologia da Universidade Federal de Pelotas (UFPEL). Parte do conteúdo dessas investigações encontra-se disponível em Fanti (2019).

${ }^{5}$ Fazemos referência aos dados reportados na pesquisa de Santos (2017), os quais são também discutidos por Santos, Silva e Miranda (2017). Nesse estudo, empreendeu-se uma investigação sobre as possibilidades através das quais a formação docente na área de "cultura e tradições ciganas" poderia contribuir para o empoderamento de crianças ciganas alunas de escolas públicas. A investigação foi conduzida em escola de Ensino Fundamental da Rede Pública da cidade de Jacobina, na Bahia. 
reorientações diversas conforme condições muito específicas. É desse modo que pensamos a constituição do estigma para o caso dos grupos ciganos, bem como da possibilidade de sua desconstrução em projetos escolares específicos, avaliando-se que tais processos devem ser analisados a partir de suas possibilidades dinâmicas. É isso que propomos perceber quando nos dispomos a estudar as condições de produção e reprodução das representações acerca desses grupos nos contextos escolares, pensando tais processos como fundamentais no âmbito das possibilidades de "descolonização de currículos" (GOMES, 2012). Por fim, é ainda necessário avaliar que tais negociações sempre ocorrem em espaços sociais através dos quais diferentes grupos ocupam posições assimétricas. Tal consideração faz pensar o jogo de representações aqui estudado no interior desses espaços (caso do campo educacional), evocando-se as perspectivas de Bourdieu (1998), as quais, em conjunto com o conceito de representações sociais, conduzem nossa análise.

Além desta introdução e notas conclusivas, o artigo é composto por mais três seções. A seção seguinte apresenta uma recuperação da historicidade tensa que refere a constituição das representações negativas projetadas sobre os grupos ciganos no contexto das sociedades ocidentais. Em seguida, a segunda seção recupera análises sobre as complexidades que envolvem a relação entre ciganos e o campo da educação, bem como estudos que abordam as possibilidades de superação dessas realidades a partir de considerações epistemológicas mais recentes sobre as práticas curriculares. Por fim, a terceira seção descreve e analisa os contextos empíricos observados, concentrando-se nos projetos educacionais vinculados à questão cigana no âmbito das comunidades escolares do sul do país.

\section{Aspectos de uma historicidade tensa: representações sobre os ciganos e o processo social do estigma}

A origem dos ciganos ainda causa dissensos entre pesquisadores de diferentes áreas. Embora parte dos ciganólogos avalie a possibilidade de que a dispersão inicial dessas populações vincule-se às incursões muçulmanas em território indiano desde o Século VI, a Índia aparecendo como espaço central dos processos diaspóricos 
subsequentes, outras narrativas relacionam sua origem ao território egípcio, caso de percepções que se demonstram recorrentes na perspectiva êmica de diferentes coletivos ciganos (PEREIRA, 2009). De qualquer modo, tratando-se de populações cujos traços culturais marcantes correspondem à oralidade e ao nomadismo, as complexidades historiográficas dizem respeito não apenas a caracterizações linguísticas, políticas e territoriais envolvidas, mas ainda aos tensionamentos sociais que acompanham a historicidade desses povos.

É possível avaliar que este conjunto de representações pejorativas foi gestado por séculos, especialmente a partir do continente europeu, cujas ações concretas redundaram inclusive em processos de escravização de ciganos, caso da Romênia do Século XV, quando aqueles povos se tornaram escravos de proprietários de terras, do Estado e da Igreja. Nesse contexto, perseguições e preconceitos foram normatizados em construções jurídicas que legitimaram não apenas as ações persecutórias, mas as próprias categorias constitutivas do estigma, ora associadas a questões religiosas (suas crenças associadas à feitiçaria por pare do catolicismo hegemônico), linguísticas (sua língua tida como propícia à burla em negociações comerciais), ao nomadismo (sua circulação vinculada à mendicância e bandidagem) ou à própria pele escura, nesse caso engendrando-se representações de cunho racista. E conforme Pereira (2009, p. 29), a partir de interações mais prolongadas estabelecidas no continente europeu iniciam-se processos de normatização daquelas representações.

A esses elementos culturais, linguísticos e religiosos — e mesmo às percepções fenotípicas da época - Moonen (2011) associa a disputa por recursos como uma das principais causas da origem do preconceito em relação aos ciganos no contexto europeu. Como destaca o autor, desde sua chegada na Europa Ocidental no início do século XV os ciganos desempenharam importantes atividades urbanas, como ferreiros, caldeireiros e artesãos, além de demonstrarem-se exímios comerciantes de cavalos e objetos diversos, o que despertou lógicas de concurso econômico. Nesses contextos, origem desconhecida e misticismo associavam-se a questões ligadas ao bem-estar material de populações dispostas em fricção territorial, engendrando-se as concepções xenófobas que posteriormente desembocaram no anticiganismo. 
Acrescenta-se a tudo isto ainda a sua cor de pele escura (segundo vários documentos: "preta"), seu aspecto "sujo", sua língua incompreensível, sua origem desconhecida, o fato de aparentemente não terem religião, os poderes mágicos das mulheres que sabiam prever o futuro e jogar pragas, tudo isto fatores adicionais que, em qualquer povo e em qualquer época, costumam provocar medo. Infelizmente, xenofobia - o medo, aversão e ódio a estrangeiros, principalmente quando constituem uma suposta ou real ameaça à vida ou ao bem-estar da população -, parece ser um fenômeno universal, difícil de ser combatido (MOONEN, 2011, p. 131).

Já com o advento da modernidade europeia, as políticas anticiganas tendem a se ampliar, tanto no que se refere à estruturação das sociabilidades típicas contidas no interior do Estado moderno (a fixação territorial como marco fundamental da ordem social), mas ainda no que concerne aos aspectos de subjetividades aparentemente opostas aos elementos demandados para a consolidação do capitalismo emergente: a vida nômade mais ligada ao comércio reciprocitário e às práticas artesanais do que à produção industrial em larga escala; ou ainda a vida de caráter comunitarista em oposição ao individualismo moderno. Assim, como descreve Scholz (2014), com a passagem do modo de produção feudal para a modernidade as perseguições aos ciganos tomam maior abrangência, e com a formação de um Estado territorial e a configuração de um pensamento propriamente capitalista, os ciganos, de vida itinerante, passam a ser concebidos como incontroláveis no cenário político e não produtivos na esfera econômica. Assim, seu modo de vida é tanto resistência quanto atributo identitário negativo na emergência do sistema capitalista.

Mas é na arte e literatura desenvolvidas nos séculos XVII e XVIII que esse conjunto de representações pejorativas até então presente na cultura popular e em algumas práticas jurídicas passa a ser organizado, emergindo uma espécie de corpo teórico do anticiganismo expresso em condenações morais que moldaram a imagem dos ciganos como "perversos", "hereges" e "selvagens", dispostos ao "banditismo", à "violência" e à "vagabundagem" (FAZITO, 2006, p. 701). Assim, autores como Gil Vicente, Cervantes, Goethe e Victor Hugo refinaram as representações oriundas dos provérbios populares, na maioria dos casos negativas. Exemplo modelar desses textos corresponde a Die Zigeuner (Os Ciganos), livro publicado por Grellman em 1783. Como best-seller, a obra foi responsável pela sistematização das teorias anticiganas e sua divulgação indiscriminada pelo mundo ocidental. Como demonstra Moonen 
(2011), o texto de Grellman compila uma série de estereótipos negativos, propondo a ideia de um suposto "canibalismo cigano", proposição que influenciou diretamente na prisão, tortura e morte de indivíduos ciganos no período de lançamento do manuscrito. Já no século XIX são as obras de George Borrow que darão continuidade à divulgação dessas perspectivas, em livros como The Bible in Spain (1843) e Lavrengo (1851), cujo conteúdo recupera e articula velhos mitos sobre ciganos, caso das supostas práticas de feitiçaria ou da famigerada ideia acerca do rapto de crianças.

Já em fins do século XIX as representações literárias se encontram conjugadas com as perspectivas supostamente científicas do período, caso das teorias deterministas formuladas a respeito da influência do meio e clima na definição do caráter de diferentes grupos humanos (BENEDICT, 1987), o ideário racista sendo definitivamente projetado sobre indivíduos ciganos. Como menciona Fazito (2006), trata-se de arranjos discursivos constituídos por um pensamento alheio às subjetividades daqueles povos (a visão ocidental sobre um outro), o qual articulou os mitos disponíveis e as categorias até então tidas como científicas. Tais concepções desembocaram numa das facetas mais dramáticas do anticiganismo com o advento do nazismo. Durante a Segunda Guerra Mundial, os ciganos tiveram seus bens confiscados pelo Estado alemão, sendo classificados como "categoria racial de mistura indeterminada" e sumariamente enviados aos campos de concentração. Avalia-se que cerca de 600 mil indivíduos ciganos foram levados ao genocídio empreendido no Terceiro Reich (SCHOLZ, 2014).

No Brasil, a chegada de grupos ciganos ocorre como parte dos processos persecutórios ocorridos no continente europeu, especialmente no que se refere às políticas anticiganistas que visavam a expulsão daqueles grupos do território português ainda na Idade Média (PEREIRA, 2009). Assim, tais coletivos desembarcam no país como degredados, portando na bagagem o acúmulo de processos repressivos e marginalização. Do ponto de vista histórico, desde o século XVIII já se constata, no Brasil, uma situação recorrente na qual ciganos não são bemvindos nos espaços urbanos em que se estabelecem, sendo comuns os conflitos e expulsões, mas ainda as estratégias adotadas pelos próprios grupos de se manter em 
movimento urbano e itinerante constante. Conforme Andrade Júnior (2013), esta parece ser a lógica da experiência social cigana nos contextos urbanos brasileiros:

[...] os ciganos tiveram de se deslocar durante pelos menos três séculos. Várias eram as leis das Câmaras Municipais que, ao receberem ciganos de outros municípios, também se apressavam em expulsá-los. No século XVIII, isso se dava quase que anualmente: mal os ciganos chegavam de uma expulsão, já tinham de se preparar para sair novamente (ANDRADE JÚNIOR, 2013, p. 8).

Ao que se verifica, os problemas enfrentados pelos ciganos no país não se restringem a esses processos de estabelecimento em territórios urbanos, estendendose por diversas áreas e diferentes campos da sociedade envolvente através dos quais o processo social do estigma ainda se reproduz. Como demonstra Andrade Júnior (2013), desde a década de 1960, no campo jurídico brasileiro, por exemplo, são recorrentes os casos em que ciganos foram acusados, julgados e sentenciados a crimes que sequer existiram, ou não tiveram qualquer acesso à defesa, observando-se penas sumariamente aplicadas. Tal lógica se mantém nas relações tensas estabelecidas com o aparato policial, quando são diversos os relatos de acampamentos invadidos e destruídos, a violência física demonstrando-se constante e acompanhada de repercussão jornalística sempre empenhada em exigir a expulsão de coletividades que supostamente representariam ameaças ao contexto social adjacente.

Decerto, muitas conquistas foram obtidas na luta pelo reconhecimento dessas populações no contexto mais recente, sobretudo no período pós-Segunda Guerra Mundial. Como notam autores como Fazito (2006) e Scholz (2014), desde as indenizações reparatórias reivindicadas junto ao Estado alemão nos anos 1960 e 1970 (ainda que em grande parte mal sucedidas), as quais articularam ações políticas conjuntas, ou mesmo no que se refere a uma certa aceitação da cultura cigana num mundo global cuja etnicidade passou a compor o repertório das identificações culturais disponíveis (HALL, 2006; SANSONE, 2003), é possível verificar avanços no combate ao preconceito em relação aos ciganos e sua cultura. Entretanto, tal possibilidade é sempre conjugada com movimentos reversos nos quais atitudes repressivas e representações negativas reorganizam os processos sociais de constituição do estigma, retomando-se, como menciona Fazito (2006), categorias discursivas e marcadores identitários historicamente acionados em desfavor daqueles 
grupos. E de forma evidente, tais processos ocorrem em diferentes espaços e campos da sociedade envolvente, o campo da educação não sendo diferente. No entanto, antes de observar o modo como esse jogo de representações se articula no interior dos espaços educacionais convém retomar os elementos teóricos básicos da discussão sobre a temática cigana no campo da educação, avaliando-se não apenas as problemáticas constatadas nos estudos disponíveis, mas ainda reflexões sobre as possibilidades de sua superação, tópicos desenvolvidos na seção que segue.

\section{Os ciganos e os espaços escolares: do campo social ao campo da educação}

Cabe ser destacado que as políticas públicas e a legislação vigente no Brasil têm sido empreendidas no sentido garantir o processo de universalização da educação e assegurar uma consideração do ensino como bem público fundamental para a ampliação da cidadania e democracia no país. As disposições constitucionais existentes, a Lei de Diretrizes e Bases da Educação Nacional e suas medidas complementares — caso da Lei $\mathrm{n}^{\circ}$ 12.796, de 2013 - encontram-se historicamente empenhadas para que crianças e jovens tenham não apenas acesso, mas ainda a permanência assegurada no sistema de ensino, sob responsabilização de seus representantes legais e do próprio Estado, com base numa caracterização específica do que compreende a educação básica, obrigatória e de acesso universal em seus diferentes níveis e em todo o território nacional.

No entanto, conforme tem sido argumentado por diferentes correntes intelectuais e políticas, para que tais prerrogativas sejam possíveis é necessário o desenvolvimento de diferentes mecanismos de proteção e reconhecimento das minorias fragilizadas, especialmente aquelas cuja experiência social é afetada por relações de desigualdade que incidem de modo efetivo em suas aproximações com o campo da educação ${ }^{6}$. Dito de outro modo, atores sociais dispostos em relações

\footnotetext{
${ }^{6}$ Nesse caso, demonstram-se recorrentes as demandas de compatibilização entre políticas universais e focalizadas para o campo da educação, quadro em que tais possibilidades têm sido acionadas em termos de políticas de ações afirmativas (MOEHLECKE, 2002; ABREU; LIMA, 2018).
} 
assimétricas no campo social mais amplo tendem a experimentar a reprodução destas mesmas desigualdades em suas possibilidades de acesso, permanência e êxito nos espaços escolares. Isso porque, em sua forma institucional moderna, a escola valoriza conhecimentos específicos na figura de arbitrários culturais universais (em detrimento de conhecimentos específicos de determinados grupos), concebendo alunos como portadores de capitais culturais distintos e, portanto, escalonados de acordo com a maior possibilidade de apropriação daqueles capitais valorizados (os conhecimentos socialmente hegemônicos) no espaço escolar (BOURDIEU, 1998) ${ }^{7}$. Nesse sentido, constata-se não apenas a existência de desigualdades de acesso e êxito nas experiências escolares, mas ainda disparidades de conteúdos e conhecimentos vinculados às estruturas curriculares oficiais (APPLE, 2001).

É desse modo que desigualdades de acesso e conteúdo podem se combinar no campo da educação, reproduzindo-se as assimetrias entre os diferentes grupos sociais no interior das instituições de ensino. Evidenciam-se, assim, diferentes lógicas através das quais esses espaços passam a ser ocupados hegemonicamente por grupos específicos, mas ainda por valores e conjuntos de representações ligados a esses mesmos grupos; ou seja: espaços onde se reproduzem não apenas as estratificações sociais propriamente ditas, mas ainda conhecimentos e representações que também se configuram como socialmente estratificados (MANNHEIM, 1968).

É essa a questão que se apresenta como recorrente para o caso dos ciganos no âmbito das práticas escolares de um modo geral. Como referido em alguns estudos (CASA-NOVA, 2006), trata-se de um grupo minoritário que encontra dificuldades não apenas de acesso junto ao campo educacional, mas ainda no que concerne aos conteúdos veiculados nesse mesmo campo (em termos de aceitação e reconhecimento de suas especificidades), o que decerto incide sobre as possibilidades de manutenção ou desconstrução dos preconceitos enfrentados na sociedade envolvente. Compreende-se ser justamente uma espécie de cisão entre mundos culturais distintos (o mundo da cultura ocidental — valorizado nas instituições da educação — em oposição à cultura cigana) que parece não apenas dificultar a inserção e permanência

\footnotetext{
${ }^{7}$ Sobre as análises do campo da educação elaboradas por Bourdieu ver ainda Nogueira e Nogueira (2002).
} 
de sujeitos ciganos no ambiente escolar, mas ainda atestar a continuidade e a propagação das representações estigmatizantes ligadas a esses grupos a partir desse mesmo ambiente.

O conhecimento acumulado por nós [...] permite-nos concluir estarmos em presença de dois sistemas culturais estruturalmente diferenciados: de um lado, uma cultura ágrafa, de transmissão oral, valorizando o pensamento concreto e o conhecimento ligado ao desempenho de atividades quotidianas que garantem a reprodução cultural e social do grupo (a cultura cigana); do outro, uma cultura letrada, de transmissão escrita, valorizando o pensamento abstrato e o pensamento erudito (a cultura da sociedade maioritária). Quando estes dois sistemas culturais se encontram no espaço escolar da sala de aula, a diferenciação cultural é duplamente evidenciada, quer através dos processos de socialização de que a criança cigana é alvo por parte da escola, quer dos papeis que aqui é chamada a desempenhar e que diferem substancialmente dos processos de socialização e educação familiares e dos papéis que desempenha dentro do grupo de pertença (CASA-NOVA, 2006, p. 161) ${ }^{8}$.

Ocorre que estas distinções em termos de processos de socialização e experimentação de papeis sociais diferenciados (no que compreende os sistemas escolares hegemônicos) atuam mais no sentido da negação da alteridade do que de compatibilização das culturas em contato, o que historicamente tem promovido não apenas o afastamento de indivíduos ciganos em relação à escola, mas a reprodução e ampliação do estigma enfrentado por essas coletividades junto à sociedade envolvente. Como demonstra Casa-Nova (2006), essa última possibilidade é promovida na medida em que os critérios de avaliação disponíveis no sistema de ensino operam através de categorias de julgamento alicerçadas na cultura dominante, as quais não apenas incidem sobre a autoestima de subjetividades cuja realidade cultural é negada, mas ainda categorizam as mesmas subjetividades em hierarquias cognitivas que comumente se definem em termos de aptidões, valores, padrões de comportamento ético e moral que potencialmente se articulam a estigmas historicamente configurados.

A escola vai gradualmente solicitando à criança cigana o desempenho de determinadas tarefas para a resolução das quais a criança vai percepcionando que os conhecimentos que possui e que são valorizados no seu grupo de pertença não

\footnotetext{
${ }^{8}$ Casa-Nova (2006) refere-se a contextos etnográficos específicos e relativos à experiência portuguesa. Contudo, como define a autora, trata-se de realidades recorrentes em diferentes países, possibilitando-se apreciações mais gerais acerca da relação entre ciganos e instituições escolares como um todo.
} 
são considerados adequados, apresentando reduzido significado para a escola, inibindo-se no desempenho de tarefas que percepciona como ameaçadoras da sua autoestima: a sua não resolução de acordo com a concepção de êxito escolarmente definido, significa a vulnerabilização da criança num meio que, não Ihe sendo hostil, é desconhecido e ameaçador na medida em que não funciona segundo as regras que conhece. Dentro do sistema cultural em que a escola se insere, e sendo ela um território socio-culturalmente territorializado, as crianças ciganas acabam classificadas em função de categorias pré-determinadas de desenvolvimento cognitivo, elaboradas pela cultura letrada e de acordo com os valores, os critérios e as normas da sociedade maioritária (CASA-NOVA, 2006, p. 161-162).

No Brasil, as políticas de reconhecimento direcionadas aos ciganos têm sido organizadas com base na caracterização desses povos como "comunidades tradicionais". Inclui-se aqui o reconhecimento da diversidade socioambiental e cultural dos grupos, considerando-se os aspectos étnicos envolvidos, rechaçando-se formas de discriminação e devendo ser garantidos os territórios e meios de acesso aos recursos necessários para a reprodução física, cultural e econômica dessas coletividades (MIRANDA, 2012). Contudo, conforme evidenciam Mazurana, Dias e Laureano (2016), em que pese a pertinência desse marco político e normativo, constata-se a falta de efetividade dessas políticas, o que se torna manifesto no campo da educação. Nesse horizonte, não se verificam iniciativas consistentes que atuem sobre problemáticas centrais, tais como as questões da itinerância e do nomadismo em relação a processos de matrícula e frequência escolar, ou mesmo no que se refere às políticas de formação de professores habilitados em lidar com as questões culturais vinculadas às especificidades do grupo.

Em relação ao nomadismo, cabe ressaltar que o Conselho Nacional de Educação, por meio da Resolução n ${ }^{\circ} 3$ de 16 de maio de 2012, tratou sobre o atendimento da educação escolar para as populações em situação de itinerância, sendo garantida a todas as crianças que vivem nessa situação a matrícula em escola pública e gratuita, sem qualquer empecilho, assim compreendendo-se os indivíduos ciganos. Porém, nesses casos, observam-se problemas de efetivação não somente no que tange aos incentivos para permanência no espaço escolar, mas também a concretização de ações facilitadoras por parte do poder público. Como mencionam Mazurana, Dias e Laureano (2006, p. 136): 
As famílias que procuram inserir as crianças nas escolas encontram muitas dificuldades por falta de políticas públicas que considerem sua cultura, em especial o fato de serem itinerantes. [Como refere uma informante]: "em cada cidade que nós ficávamos, por exemplo, se ia ficar 15 dias, a gente botava nossa filha 13 dias na escola". Apesar deste esforço, as famílias em geral desistem rapidamente em função do preconceito.

Conforme a descrição acima fica notória a relação entre a presença e/ou persistência dos indivíduos ciganos nas instituições escolares e a dimensão alcançada pelas representações do estigma que parecem se atualizar nesses espaços, o que é promovido a partir das dificuldades de mediação cultural recorrentemente percebidas nesses ambientes e nessas situações:

Nenhuma mãe quer ver seu filho sofrendo ou ser humilhado dentro de uma escola. O modo de vestir, o assédio para que as crianças leiam a mão e outras formas de violência e constrangimento por parte de colegas, profissionais da educação e comunidade escolar, alimentados pelo imaginário de que o povo cigano rouba crianças, criam ambientes de desconforto, medo e insegurança, além de ser uma violação de direitos das famílias ciganas. Encontrar uma escola acolhedora pode ser determinante para definir o local de residência fixa (MAZURANA; DIAS; LAUREANO, 2006, p. 136).

Aqui pode-se perceber o constrangimento pelo qual muitas crianças ciganas passam na escola brasileira, o que se revela na figura de um ambiente hostil arranjado em torno dos estereótipos criados historicamente e cujas bases decorrem da segregação do grupo na esfera pública, nas interações e sociabilidades cotidianas, atualizando-se nos bancos escolares. Trata-se da agência ligada a uma violência simbólica que não apenas anula os processos de alteridade, mas legitima as premissas da cultura dominante, assim estabelecendo-se uma ordem gnosiológica de representações cujo sentido naturaliza as diferenças sociais e suas consequentes hierarquias simbólicas (Cf. BOURDIEU, 1989)ำ. Decerto, tais representações geram ações e consequências práticas na experiência desses indivíduos, podendo afastá-los

\footnotetext{
${ }^{9}$ A ideia de violência simbólica é aqui acionada no sentido de Bourdieu (1989), vinculandose aos efeitos ideológicos contidos na imposição de sistemas classificatórios que não apenas "constroem" a realidade, mas ainda estabelecem um conformismo lógico que assegura a reprodução não contraditória da sociedade em seus diferentes espaços, caso do próprio campo educacional, assim observando-se a manutenção das estruturas de poder disponíveis.
} 
da educação básica e, por conseguinte, do ensino superior, situação que potencialmente gera um ciclo vicioso no qual a fragilização educacional liga-se à precarização de articulações políticas futuras, gerando-se o desconhecimento dos direitos e dificuldades de acesso às políticas públicas e condições de cidadania.

Ampliando tal perspectiva, conforme tem sido evidenciado na literatura disponível (LOURENÇO; OLIVEIRA; CORREIA, 2008; MAZURANA; DIAS; LAUREANO, 2006; SILVA, 2017; SANTOS; SILVA; MIRANDA, 2017), a problemática da escolarização de crianças ciganas no Brasil ocorre desde sua chegada à escola, situação na qual a negociação da alteridade apenas ressalta de modo problemático as diferenças culturais, o que dificulta sobremaneira a integração desses indivíduos ao grupo escolar e às sociabilidades estudantis, tendo em vista ser comum que uma série de estereótipos negativos passe a ser projetada sobre essas crianças justamente neste momento. Se o preconceito vivido como experiência estudantil já se configura como processo doloroso, dramático e potencialmente traumático, ainda os conteúdos ministrados não contemplam a forma de ver o mundo ou os conhecimentos tradicionais daqueles agentes, considerando-se aqui que a diversidade étnico-cultural nem sempre é contemplada no arcabouço curricular disponível. Tal perspectiva evidencia, portanto, que a reflexão sobre as estratégias pedagógicas possíveis para lidar com essas problemáticas passa necessariamente por uma discussão acerca das práticas curriculares e da possibilidade de sua descolonização.

Nessa perspectiva, com base em Lourenço, Oliveira e Correia (2008), se é possível constatar, como em Casa-Nova (2006), que o espaço escolar opera cindindo universos culturais distintos (a cultura hegemônica em oposição à cultura cigana), pareceria ser justamente o processo inverso um meio de inserção e aceitação das crianças ciganas no ambiente escolar; ou seja: a experiência transcultural, calcada não apenas em atividades próprias da sociabilidade cotidiana, mas nas práticas e empreendimentos de um currículo multicultural, assim tornando-se a experiência educacional daqueles indivíduos como parte de um processo pedagógico plural e acolhedor. De acordo com Lourenço, Oliveira e Correia (2008), é necessário saber respeitar os saberes oriundos da cultura na qual o sujeito está integrado, 
rentabilizando-os estrategicamente junto aos procedimentos de ensino e aprendizagem:

Sendo a escola a instituição de socialização/integração à cultura dominante, é fácil perceber como ela representa, no caso da criança cigana, não uma continuidade do trabalho iniciado pela família, mas a ruptura com os valores assimilados no seio familiar. A criança, ao entrar para a escola, é portadora de saberes, fruto de experiências herdadas pelas gerações adultas do grupo [...] Conceber atividades educativas que vão de encontro aos conhecimentos de que os diferentes grupos socioculturais são portadores, que não destrua mas rentabilize e que estimule o respeito pelas raízes culturais parece ser uma estratégia com possibilidade de captar e desenvolver o interesse das crianças ciganas e de outros grupos minoritários (LOURENÇO, OLIVEIRA; CORREIA, 2008, p. 13-15).

Neste sentido, como preconiza Gomes (2012), surgem como necessários os empreendimentos que buscam repensar os currículos a partir de processos de descolonização, para tal devendo ser superado o eurocentrismo acadêmico e valorizadas as experiências multiculturais características e fundantes das sociedades plurais. Nesses processos, como refere Gomes (2012), trata-se de dar voz e vez para as culturas oprimidas, fragilizadas e silenciadas, assim possibilitando-se processos mais amplos de reconhecimento e acolhimento de sujeitos e grupos, caso dos ciganos no ambiente escolar brasileiro. Contudo, para pensar tais possibilidades, torna-se relevante avaliar as iniciativas pedagógicas disponíveis e com propósitos similares, observadas a partir de projetos educacionais específicos empreendidos em diferentes contextos, caso das ações pedagógicas que passamos a analisar.

\section{Falando sobre os ciganos no espaço escolar: projetos educacionais alternativos em contextos específicos}

O projeto educacional que aqui expomos como relato de experiência empírica principal ocorreu na Escola Municipal de Ensino Fundamental Dr. Rui Poester Peixoto, situada no bairro São Miguel, região periférica da cidade de Rio Grande. Atualmente, a escola atende um contingente de cerca de mil alunos, em sua maioria moradores do entorno escolar, basicamente filhos de atores sociais diversos como pescadores, agricultores, comerciantes e funcionários do comércio local. Entre os escopos do Projeto Político Pedagógico da escola encontram-se premissas como a 
formação de sujeitos "além de meros operários", bem como de cidadãos capazes de desenvolver as "competências necessárias para a prática da cidadania responsável”10.

De modo sazonal, a escola desenvolve diferentes atividades e programas vinculados a questões como sustentabilidade, práticas desportivas, estruturação das relações familiares e comunitárias, além de um projeto educacional anual ligado ao fortalecimento de práticas interdisciplinares cujas temáticas alternam-se a cada edição. Foi a partir deste último modelo de projeto que, no ano de 2016, foram desenvolvidas atividades conjugadas sob a temática das relações étnico-raciais, nas quais, além das questões afro-indígenas, obteve destaque a temática dos povos ciganos. Como metodologia, as turmas foram divididas em grupos, cada qual trabalhando etnias específicas sobre as quais se realizaram pesquisas temáticas mais aprofundadas. Os resultados foram expostos para toda a comunidade envolvente a partir de uma Mostra de Trabalhos, a qual contou com feira temática de produtos e apresentações teatrais, cada atividade estando relacionada às perspectivas culturais dos grupos envolvidos.

Conforme a Supervisora da Escola, a proposta de inserir a temática dos povos e cultura cigana na edição de 2016 partiu da necessidade de articular diferentes campos do saber com as demandas por familiarizar o corpo docente com possíveis alunos ciganos $^{11}$, o que se deve não apenas à presença de coletivos ciganos no entorno da cidade, mas ainda em virtude da jurisdição própria das Comunidades Tradicionais em suas vinculações com o campo da educação e as atuais propostas curriculares:

\begin{abstract}
A ideia era começar a familiarizar os alunos e professores da escola com possíveis alunos ciganos. É isso que tentamos fazer com esse projeto. Agente criou um projeto que falasse de negros, índios e ciganos em que todas as disciplinas atuassem, de modo interdisciplinar. A cultura cigana foi trabalhada pelo oitavo e nono anos, quando os alunos fizeram pesquisa sobre a cultura desses povos e logo apresentaram para a comunidade ${ }^{12}$.
\end{abstract}

\footnotetext{
10 Informações coletadas no Projeto Político Pedagógico disponibilizado pela Escola.

${ }^{11}$ No momento de realização do projeto, bem como de realização das entrevistas, a Escola não possuía alunos ciganos dentre aqueles matriculados em seus quadros.

${ }^{12}$ Carla Rosane Viana Pedra, Supervisora da Escola, em entrevista realizada em julho de 2019. Optamos por utilizar os nomes reais de nossos informantes, não apenas pelo fato dos mesmos estarem cientes da proposta da pesquisa realizada e de acordo com a gravação e reprodução das entrevistas, mas ainda em virtude do conteúdo do trabalho e das informações prestadas não apresentarem implicações de ordem ética.
} 
A pesquisa e exposição temática relativa aos ciganos foi trabalhada por alunos e alunas com idade entre 12 e 16 anos. Nesses casos, os mesmos puderam confeccionar cartazes, apresentar suas pesquisas por meio de slides ou de forma oral, maquetes, folhetos informativos e assim por diante, ainda realizando apresentações teatrais e feira de comidas típicas em edificação improvisada e denominada "cabana cigana". Conforme refere a Supervisora, em sua perspectiva o evento foi bem sucedido, docentes, pais e alunos tendo atuado de maneira dedicada junto à efetivação da proposta, percebendo-se como saldo a vontade dos envolvidos em buscar maior familiarização com a cultura tratada. Ainda segundo a informante, a importância da ação consiste no fato de que outros grupos minoritários (como indígenas e afrobrasileiros) já ocupam espaço determinado nos componentes curriculares formais (sendo contemplados em disciplinas como história, por exemplo), o mesmo não ocorrendo com a temática dos ciganos, a qual ainda necessita desse tipo de atividade para receber espaço de debate no ambiente escolar.

Por sua vez, as possíveis resistências ao projeto partiram de agentes de confissão evangélica. Como nos refere uma informante, tal fator pode ter sido motivado por questões de ordem religiosa, o que provavelmente decorre de uma percepção muito comum em meio ao campo das religiões populares no Brasil acerca da apropriação da cultura cigana por parte de determinados rituais ligados às religiosidades afro-brasileiras ${ }^{13}$. Nesses casos, observam-se lógicas de resistência à alteridade que decorrem das complexidades próprias do campo religioso do país, com base na constante oposição que segmentos evangélicos destinam a outras formas religiosas populares. Como demonstram alguns estudos, tal resistência parece se ampliar para além dos escopos do campo religioso, inserindo-se sob diferentes formas nos próprios domínios do campo educacional (FIOROTTI, 2019).

Uma das professoras responsáveis pelo projeto, docente da disciplina de história há cerca de cinco anos referiu ser a primeira vez em sua trajetória acadêmica que trabalhava com a temática dos ciganos em projeto pedagógico específico. Nesse

\footnotetext{
${ }^{13}$ Como se sabe, diferentes vertentes do campo das religiões afro-brasileiras, como a Umbanda, cultuam espíritos de antepassados da sociedade brasileira, em alguns casos sendo cultuados espíritos de ciganos e ciganas. Para informações sobre esses cultos ver o trabalho de Silva (2005).
} 
sentido, não recorda ter refletido sobre a questão em sua graduação e menciona que, em seu percurso formativo, não obteve informações sobre a obrigatoriedade de temáticas similares em termos curriculares. É justamente este ineditismo da abordagem junto ao tema em sua trajetória que também se demonstra instigante para a análise aqui empreendida, não apenas no que compreende as possibilidades pedagógicas encontradas (já que a mesma foi a responsável pelo projeto), mas o modo como o próprio projeto educacional voltado aos ciganos alterou sua percepção docente para as questões levantadas, assim permitindo-nos uma visão sobre a ação do projeto não apenas em relação aos alunos, mas em relação ao próprio corpo docente.

Para inserir a proposta em sala de aula, inicialmente a professora solicitou aos alunos que relatassem o que sabiam sobre ciganos, que ciência possuíam sobre sua cultura, seu modo de vida, propondo indagações para iniciar os diálogos. No entanto, as respostas obtidas — em momento inicial e preparatório dos projetos — eram bastante negativas e estereotipadas, na grande maioria dos casos denominando-se os indivíduos ciganos como "beduínos", "trapaceiros" e "enganadores". Nesse sentido, os alunos respondiam que seus familiares mencionavam ideias como "cigano é ladrão", "rouba crianca", "beduino engana"; ou que "todos os ciganos moram embaixo de uma tenda"; que mulheres ciganas são "muito escandalosas"; ou ainda que se trata de "um grupo que não deve ser de confiança". Em outras narrativas, afirmou-se que suas práticas místicas, como a adivinhação, leitura de mão e jogo de cartas "são tudo mentira, sem fundamento nenhum", consistindo apenas em artimanhas para "enganar as pessoas".

Essas representações pejorativas também aparecem nas narrativas de alunos não apenas como marcadores da alteridade (a definição do outro cigano), mas como recurso que mobiliza o estigma desse mesmo outro como meio para obtenção de determinadas atitudes, como quando os pais ameaçam os filhos (em troca do comportamento desejado) reforçando a negatividade da identidade cigana: "se não te comportares vou te dar para os beduinos" [...] "Vou te deixar no acampamento dos ciganos" [...] "Quero ver como vais te comportar quando for morar com os ciganos". Contudo, seja com base em representações diretamente projetadas sobre um determinado outro, ou ainda acionadas na mobilização do estigma com determinados fins instrumentais, o que se compreende é que o conhecimento que os alunos detinham sobre os ciganos e sua 
cultura correspondia ao senso comum transmitido por parte do núcleo familiar, dos meios midiáticos e da sociedade como um todo. Como refere uma professora, "era a [informação vinda] de casa, que eles trąiam para a escola, era de senso comum, [sendo que] reproduziam o que escutavam, mas sem saber se era verdade. Falavam porque o pai falava e o pai falava porque a avó falava e assim sucessivamente"14.

Se a transmissão dessas representações vai ocorrendo sem muita reflexão por parte dos agentes reprodutores, apenas constatando-se marcadores pejorativos de algum modo recorrentes, o mesmo não se observa, logicamente, para o caso da experiência dos indivíduos ciganos em relação a tais realidades. É o que se pode avaliar das narrativas encontradas em campo de investigação, que nos revelam experiências profundamente afetadas por aquele conjunto de enunciações aparentemente despretensiosas e acionadas no cotidiano escolar. A diferença parte de que, na visão de ciganos, não se trata de marcadores negativos específicos que vão sendo projetados sobre sua subjetividade (ideias como "trapaça", "roubo" ou "escândalo"), mas da própria condição de "ser cigano" por si só sendo acionada como elemento negativo ou motivo de ação repressiva nas interações escolares. É o que nos revelam as memórias de ciganas como Jeniffer, nunca chamada pelo nome por parte dos colegas de aula em seu tempo de criança, mas sempre perseguida na saída da escola sob constantes acusações de "ser cigana". Ou ainda as memórias de Luiza, cujo filho fora "acusado de ser cigano" por faltar algumas aulas, em ocorrências motivadas por um real problema de saúde (não considerado verídico por parte dos professores) ${ }^{15}$. Em ambos os casos, a saída da escola foi a solução encontrada para lidar com as situações.

Contudo, é devido destacar que as representações baseadas em marcadores pejorativos dicotômicos se demonstram centrais nas falas de indivíduos não ciganos. Assim, marcadores similares aos encontrados em Rio Grande são aparentes na comunidade escolar estudada por Santos (2017), na cidade baiana de Jacobina, na qual as principais categorias acionadas nas narrativas disponíveis correspondem a ideias

\footnotetext{
${ }^{14}$ Melissa Oliveira, docente da disciplina de história, em entrevista realizada em setembro de 2018.

${ }^{15}$ Jeniffer e Luiza são ciganas da etnia Rom, do subgrupo Kalderash, atualmente residentes na região sul do Rio Grande do Sul. Suas declarações foram obtidas em conversas informais registradas em diário de campo, o que se deu a partir de incursões etnográficas realizadas em fevereiro de 2018.
} 
como "medo", "trapaça", "roubo", "dúvida", "leitura de mãos", etc. Como se observa, em ambos os contextos trata-se de conjuntos de representações historicamente recorrentes e projetadas sobre um "outro genérico", as quais se organizam a partir de categorias depreciativas e mais ou menos estáveis como "burla", “engano”, “trapaça”, "roubo”, “mentira”, "violência” e “escândalo”. Nota-se que são categorias geralmente acionadas como contraponto a comportamentos ou atitudes tidas como referência: a "lisura", a "boa-fé", a "sinceridade", a "verdade", a "paz", a "normalidade" e etc. Contudo, como se sabe desde Mary Douglas (1976), se essas oposições binárias operam como eixo fundamental de processos de representação acerca de diferentes identidades (nesse caso constituintes do estigma), ao mesmo tempo elas conferem a seus portadores certo poder simbólico relativo à proximidade que mantém com relação às margens (simbólicas ou reais). E é justamente essa proximidade com espaços simbólicos ligados ao "perigo" e à "incerteza" o que desperta fascínio, daí decorrendo as possibilidades de consumo estético relativo às culturas ciganas e as ideias de "encantamento" que por vezes emergem no contexto das comunidades escolares.

Essas últimas possibilidades são encontradas tanto no contexto baiano de Jacobina, investigado por Santos (2017), quanto no projeto educacional da escola gaúcha aqui analisado. No caso referenciado em Santos (2017), uma vez que as narrativas sobre ciganos passam a ser problematizadas de acordo com uma progressão rumo a entrevistados mais velhos e integrantes do corpo docente (que em oficinas sobre o tema promovem uma relação entre suas memórias "sobre ciganos" e suas trajetórias acadêmicas), outros marcadores mais positivos começam a aparecer, o que provavelmente decorre de processos formativos mais amplos e do contato com noções acerca da interculturalidade e diferença cultural. Nesse sentido, ideias como “alegria", "festas", "brilho", "valentia”, "fartura" e "fascínio" começam a emergir, possivelmente articulando-se a perspectivas estéticas amplamente disseminadas em estratégias identitárias características do globalismo multicultural. Tais possibilidades também emergiram de modo importante no projeto educacional visualizado no contexto gaúcho. Como mencionou a Supervisora da Escola, pais e alunos demonstraram-se "encantados" com elementos básicos da cultura cigana, 
especialmente no caso das danças e vestimentas, "o que levou até mesmo alguns atores evangélicos [possivelmente refratários ao contato com aquelas práticas] a ficarem orgulhosos de verem seus filhos vestidos e participando das danças". Decerto, tais perspectivas não se encontram necessariamente livres de noções preconcebidas e reduzidas a uma dimensão estereotipada da cultura cigana, embora, nesses casos, já constatando-se tendências importantes de predisposição à aceitação da alteridade. Ampliando tal possibilidade, talvez resida justamente nessa tendência alguns princípios básicos para a efetivação dos projetos educacionais empreendidos nessas escolas.

Segundo a professora que orientou o projeto na escola de Rio Grande, a ideia da Mostra de Trabalhos era de que os alunos não apenas produzissem um relatório final, mas que se oportunizasse um processo de divisão dos conhecimentos obtidos durante toda execução da pesquisa, assim lhes sendo incentivado a pensar e partilhar o conhecimento nas interações que envolviam o período de efetivação dos trabalhos, na escola ou em casa. Destacou a professora que "na aula, os grupos (alunos) começavam a comentar o que descobriram sobre os ciganos", constatando-se uma permanente troca de informações e conhecimentos, com diálogos através dos quais abordavam as especificidades culturais que mais lhes despertavam curiosidade (o batismo e o casamento cigano, etc.), em processos contínuos de comparação entre as diferenças e diversidades constitutivas da sociedade na qual todos estão inseridos. A todo o momento, nos debates de sala de aula, quando alguma representação negativa era eventualmente recuperada, a metodologia acionada consistia na prática insistente do questionamento sobre ideias aparentemente "dadas": "como sabiam disso; se poderiam provar; como poderiam ter certeza", logo sendo pontuado que não apenas poderiam estar equivocados em relação a tais noções, mas ainda que o estudo e o conhecimento mais aprofundado do tema poderia mudar tal perspectiva: "é isso mesmo? Ciganos moram assim? Ciganos vivem desse jeito? Eles realmente se aproximam das pessoas com o intuito tirar vantagem?’.

No decorrer dos projetos, as representações iniciais até então negativas começaram a mudar, sendo percebido que os marcadores pejorativos geralmente imputados a ciganos e suas práticas não se mantinham, tais ideias sendo desconstruídas pelas próprias informações que emergiam das atividades de pesquisa. Assim, a maioria de alunos e alunas passaram a olhar a cultura e o indivíduo cigano 
sob nova perspectiva, a cada encontro demonstrando-se mais atentos e dedicados ao tema. Como refere a mesma docente, em sua maioria os alunos "ficaram encantados com a oralidade, o dialeto, a ideia da comunicação que ninguém entende, que é só deles, o grupo fechado entende, eles [alunos] ficaram encantados. No meu entendimento, foi o ápice do trabalho". E quando questionada sobre possíveis mudanças nas perspectivas dos discentes ao final das pesquisas, destacou:

Os alunos que participaram do trabalho desde o início, que estavam abertos à pesquisa, que trouxeram as mesmas experiências, as falas do avô, avó, tios, das pessoas mais antigas da família, da questão preconceituosa, do trato, o que eles (ciganos) são, que vão roubar [...] Estes eu senti que conseguiram desfazer esse estigma do povo cigano. [Mas] aquele aluno que disse [desde o início das pesquisas] que não iria participar, [esse] não. Outras pessoas [alunos e pais], que eu visualmente percebi que não queriam fazer, mas participaram, acho que elas ainda vão precisar de mais provas pra entender o que eles [ciganos] são. Mas neste caso, mesmo não querendo, acredito que pelo fato de não se mostrarem contrários ao trabalho já ajudou. Com certeza, esses que fizeram, que era a grande maioria que quis participar, estes se tornaram multiplicadores para o fim daquela concepção, para o fim daquele estigma ${ }^{16}$.

Como se percebe, embora com diferentes níveis de envolvimento e aceitação da alteridade, a maior parte dos alunos e alunas reconheceu as especificidades da cultura cigana, passando a descontruir as representações preconceituosas sobre os sujeitos ciganos, constituindo-se uma nova visão acerca desses povos e suas práticas, mais humana, respeitosa e integradora. Decerto, ainda que se evidencie a permanência do processo social do estigma, presente em nossa sociedade através de um conjunto de representações negativas que se atualizam em diferentes espaços - como nas próprias comunidades escolares —, considera-se que os projetos educacionais aqui empreendidos operam no sentido de articular representações alternativas em contextos através dos quais certas temáticas ainda não encontram-se contempladas nas matrizes curriculares disponíveis. Como alguns dados sinalizam, tais projetos também possibilitam atitudes de questionamento e problematização, por parte do corpo docente, sobre as demandas curriculares aqui mencionadas, como se observa

\footnotetext{
${ }^{16}$ Professora Melissa Oliveira, em entrevista realizada em setembro de 2018.
} 
nos relatos de diferentes professores que, de modo recorrente, passam a refletir sobre as possibilidades de inserção dos temas abordados em seus campos disciplinares ${ }^{17}$.

\begin{abstract}
Sim, esse trabalho foi motivado pela escola, mas dentro do nono ano, quando nós trabalhamos as principais guerras, se abrisse a brecha [...] no momento que está se trabalhando a Segunda Guerra Mundial, tu tens que falar sobre os ciganos, é impossível, não que não se possa falar em outro espaço, mas um espaço concreto dentro da nossa grade de ensino, existe este espaço, sim. Tu elencas várias obras da Segunda Guerra e os judeus, A lista de Schindler, A menina que roubava livros, 0 menino do pijama listrado [...] Mas dos ciganos não, sendo difícil encontrar literatura e até no material didático não é contemplado. Foi difícil até para os alunos na pesquisa encontrar material, o que foi encontrado estava na internet ${ }^{18}$.
\end{abstract}

Como é possível avaliar, embora possam ser concebidos como empreendimentos sazonais e deliberados de modo aparentemente aleatório, os projetos educacionais voltados ao estabelecimento do debate e desconstrução do estigma de determinados grupos apresentam potencial interessante não apenas para reelaborar as lógicas de representação negativas acerca desses coletivos, mas ainda para gerar reflexividade sobre a organização curricular disponível por parte dos agentes que compõem os quadros docentes.

\title{
Algumas considerações para o debate
}

No transcorrer deste trabalho, mediante recuperação de literatura especializada e contato com algumas realidades empíricas disponíveis procuramos discutir possibilidades concretas para o estabelecimento do diálogo acerca dos grupos ciganos e sua cultura no ambiente escolar. Neste sentido, tratou-se de pensar, especialmente a partir dos projetos educacionais específicos colocados sob observação, diferentes modos pelos quais a escola pode tornar-se um espaço plural e acolhedor, sendo instrumento de combate à discriminação e preconceito, assim reconhecendo a

\footnotetext{
${ }^{17}$ Essa possibilidade aparece nos dados coletados em Rio Grande, mas também no contexto estudado por Santos (2017), em situações nas quais os projetos educacionais empreendidos ensejaram reflexões sobre a possível abordagem da temática cigana nos currículos regulares.

18 Professora Melissa Oliveira, em entrevista realizada em setembro de 2018.
} 
diversidade a partir de processos pedagógicos voltados à integração dos diferentes saberes e práticas culturais, bem como de subjetividades e identidades múltiplas.

Como haveria de se esperar, para o caso de grupos largamente perseguidos e cuja historicidade tem se configurado a partir de relações tensas estabelecidas com a sociedade envolvente, certas lógicas de representação estigmatizantes tendem a se reproduzir em diversos espaços sociais, e os espaços escolares não se encontram imunes a tais realidades. Ao contrário, conforme as representações elaboradas mais comumente por alunos e alunas acerca da temática dos ciganos, detecta-se a permanência de marcadores pejorativos sobre esses povos e sua cultura, os quais ainda organizam percepções sociais mais ou menos estáveis e ancoradas em oposições de categorias como "trapaça", "roubo", "mentira" e "violência" em contraposição a noções como "lisura", "honestidade", "verdade" e "normalidade". Contudo, se a escola (assim como outros tantos espaços sociais) não corresponde apenas a um universo estruturado de reprodução simbólica, mas a um campo estruturante e composto por negociações tensas da realidade, é presumível que mediante práticas pedagógicas que questionem aquelas representações supostamente "estáveis" novos processos representacionais sejam possíveis, as lógicas de identificação que organizam o estigma de certos grupos sendo desestabilizadas ou desconstruídas.

É isso que se observa quando realidades aparentemente "dadas" passam a ser problematizadas pelos alunos nos projetos empreendidos, quando novas visões e imagens acerca dos ciganos e suas culturas emergem de modo contínuo nas pesquisas realizadas. Trata-se de novos esquemas conceituais e de percepção que passam a ser socializados no contexto educacional (em socializações de segunda ordem) mediante procedimentos que encontram nas conversas estudantis ou nas atividades de pesquisa seus principais rituais de alteração, conservação ou confirmação da realidade (BERGER; LUCKMANN, 2002). É justamente aqui que parecem emergir, no âmbito desses projetos, as possibilidades de desconstrução de estigmas e visões preconceituosas, em cujas pesquisas e debates de sala de aula novas representações vão sendo configuradas e contrapostas ao senso comum estereotipado acerca de determinadas categorias sociais. 
Decerto, perceber a escola como um espaço de negociações da realidade através do qual representações, percepções e lógicas de identificação podem ser reorganizadas e redefinidas — com base em projetos e ações pedagógicas de metodologias variadas — não significa atestar que projetos sazonais como aqueles aqui retratados possibilitem reordenar as assimetrias próprias do campo educacional, em termos de acesso ou conteúdo, nesse último aspecto considerando as necessárias demandas de descolonização dos currículos. No caso das práticas curriculares, a descolonização mediante propostas de tradução cultural demandaria, inclusive e de modo impreterível, a participação ativa dos sujeitos pertencentes às culturas negadas e silenciadas (a tradução intercultural só sendo possível articulando-se as diferenças entre culturas com base no contato), o que tem se demonstrado complexo para o caso dos ciganos, cuja presença nos espaços escolares é extremamente relativa e nem sempre factível nos períodos de execução daqueles projetos. Ainda assim, como se observa nesses intentos, seja em projetos voltados aos alunos ou ao corpo docente, o saldo dessas experiências parece apontar não apenas para lógicas de ruptura com as representações mais estabilizadas, mas para a emergência de reflexividades no próprio corpo docente — isso no que concerne aos arranjos curriculares disponíveis —, aqui residindo possibilidades efetivas de ampliação das discussões acerca dos processos de descolonização das práticas curriculares. Em tais procedimentos, a abordagem de coletividades dotadas de saberes e fazeres tradicionais deve reconhecer suas especificidades, através de metodologias que potencializem a integração de alunos e alunas em práticas de escolarização que respeitem a diversidade, o pluralismo e o diálogo intercultural.

\section{Referências}

ABREU, E. N.; LIMA, P. G. Políticas de ações afirmativas: itinerário histórico e pontuações quanto à realidade brasileira. Laplage em Revista, v. 4, n. 2, p. 179-196, 2018.

ANDRADE JÚNIOR, L. Os ciganos e os processos de exclusão. Revista Brasileira de História, v. 33, n. 66, p. 95-112, 2013.

APPLE, M. Repensando Ideologia e Currículo. In: MOREIRA, A. F.; SILVA, T. T. (Orgs.) Currículo, Cultura e Sociedade. São Paulo: Ed. Cortez, 2001. p. 39-57. 
BENEDICT, R. Raza: ciencia y política. México: Fondo de Cultura Económica, 1987.

BERGER, P.; LUCKMANN, T. A construção social da realidade: tratado de sociologia do conhecimento. Petrópolis: Editora Vozes, 2002.

BOURDIEU, P. Escritos de Educação. Petrópolis: Vozes, 1998.

BOURDIEU, P. O poder simbólico. Lisboa: DIFEL, 1989.

CASA-NOVA, M. J. A relação dos ciganos com a escola pública: contributos para a compreensão sociológica de um problema complexo e multidimensional. Interacções, n. 2, p. 155-182, 2006.

DOUGLAS, M. Pureza e Perigo. São Paulo: Editora Perspectiva, 1976.

FANTI, M. P. Cultura e identidade cigana: uma análise do movimento de sedentarização de grupos ciganos na região sul do Brasil. Monografia Final (Curso de Especialização em Sociologia). Programa de Pós-Graduação em Sociologia (Lato Sensu), Universidade Federal do Rio Grande, Rio Grande, RS, 2019.

FAZITO, D. A identidade cigana e o efeito 'nomeação': deslocamento das representações numa teia de discursos mitológicos-científicos e práticas sociais. Revista de Antropologia da USP, v. 49, n. 2, p. 689-729, 2006.

FIOROTTI, S. Intolerância religiosa dos evangélicos na educação básica: breve análise de alguns casos. Interritórios, v. 5, n. 9, p. 213-231, 2019.

GOFFMAN, E. Estigma: notas sobre a manipulação da identidade deteriorada. Rio de Janeiro: LTC, 2017.

GOMES, N. L. Relações étnico-raciais, educação e descolonização dos currículos". Currículo Sem Fronteiras, v. 12, n. 1, p. 98-109, 2012.

HALL, S. A identidade cultural na pós-modernidade. Rio de Janeiro: DP\&A, 2006.

LOURENÇO, A. R.; OLIVEIRA, A. R. L.; CORREIA, C. E. S. A criança cigana e a escola. Porto: Escola Superior de Educação Paula Frassinetti (Portugal), 2008.

MAFFESOLI, M. Sobre o nomadismo: vagabundagens pós-modernas. Rio de Janeiro: Record, 2001.

MANNHEIM, K. Ideologia e Utopia. Rio de Janeiro: Zahar Editores, 1968.

MAZURANA, J.; DIAS, J. E.; LAUREANO, L. C. Povos e Comunidades Tradicionais do Pampa. Porto Alegre: Fundação Luterana de Diaconia, 2016.

MIRANDA, A. C. Povos e comunidades tradicionais: análise do processo de construção sociológica e jurídica da expressão. Dissertação de Mestrado. Programa de Pós-Graduação em Ciências Sociais, Universidade Federal do Maranhão, São Luís, Maranhão, 2012.

MOEHLECKE, S. Ação afirmativa: história e debates no Brasil. Cadernos de Pesquisa, n. 117, p. 197-217, 2002. 
MOONEN, F. Anticiganismo: os ciganos no Brasil e na Europa, 2011. Disponível em http://www.dhnet.org.br/direitos/sos/ciganos/. Acesso em: 01 jun. 2020.

MOSCOVICI, S. Os ciganos entre perseguição e emancipação. Sociedade e Estado, v. 24, n. 3, p. 653-678, 2009.

MOSCOVICI, S. Representações Sociais: investigações em psicologia social. Petrópolis, RJ: Vozes, 2003.

NOGUEIRA, C. M.; NOGUEIRA, M. A. A sociologia da educação de Pierre Bourdieu: limites e contribuições. Educação e Sociedade, n. 78, p. 5-36, 2002.

PEREIRA, C. C. Os ciganos ainda estão na estrada. Rio de Janeiro: Rocco, 2009.

SANSONE, L. Negritude sem etnicidade: o local e o global nas relações raciais e na produção cultural negra do Brasil. Salvador/Rio de Janeiro: Edufba/Pallas, 2003.

SANTOS, L. C. Etnicidade e educação: formação docente sobre povos ciganos na Escola Municipal Agnaldo Marcelino Gomes. Dissertação (Mestrado em Educação e Diversidade) — Universidade do Estado da Bahia, Jacobina, Bahia, 2017.

SANTOS, L. C.; SILVA, J. J. C.; MIRANDA, C. A. S. A(s) cultura(s) ciganas no espaço escolar: a formação docente como experiência inovadora na escola Agnaldo Marcelino Gomes”. Revista de Estudos e Investigacões Antropológicas, v. 4, n. 2, p. 67-91, 2017.

SCHOLZ, R. Homo Sacer e os ciganos: o anticiganismo — reflexões sobre uma variante essencial e por isso esquecida do racismo moderno. Lisboa: Antígona, 2014.

SILVA, V. G. da. Candomblé e Umbanda: caminhos da devoção brasileira. São Paulo: Selo Negro, 2005.

SILVA, L. A. R. da. Desafios para efetivação do direito à educação: com a palavra, os ciganos. Dissertação (Mestrado em Políticas Sociais e Cidadania) - Universidade Católica de Salvador, Salvador, Bahia, 2017.

THOMAS, W. La definición de la situación. Cuadernos de Información y Comunicación, Santiago de Chile, n. 10, p. 27-32, 2005.

RECEBIDO: $22 / 03 / 2021$

APROVADO: $22 / 09 / 2021$

RECEIVED: 03/22/2021

APPROVED: 09/22/2021

RECIBIDO: $22 / 03 / 2021$

APROBADO: 22/09/2021 